\title{
Music Assessment in Higher Education
}

\author{
John A. Fuller \\ North Carolina State University, Raleigh, USA \\ Email: jafuller@ncsu.edu
}

Received 30 April 2014; revised 4 June 2014; accepted 11 June 2014

Copyright (C) 2014 by author and Scientific Research Publishing Inc.

This work is licensed under the Creative Commons Attribution International License (CC BY). http://creativecommons.org/licenses/by/4.0/

(c) (i) Open Access

\begin{abstract}
The purpose of this study is to determine the type and level of assessment being done at selected music departments in higher education. A twelve-item questionnaire was developed and distributed to twenty-two universities. Sixteen universities were chosen because they are the peer institutions to the author's campus. The others do not have music major but possess other strengths including several ensembles, many courses for students to choose from and in many cases, a minor in music. Cover letters and questionnaires were emailed to the Director of each Music Department. The cover letter explained the purpose of the questionnaire and asked that the director forward it to the individual in charge of assessment. Eleven universities responded. Results of this study indicate that assessment is going on in higher education in music. Although there were only eleven institutions involved in the study, every responding university indicated that they were doing some kind of assessment in music. The degree of assessment varied from campus to campus. Assessment training and support was limited. But, eleven music departments nationwide feel the need (and responsibility) to examine what and how they are teaching and then to come up with decisions on how to improve their teaching. Further, they feel that implementation of reviewed assessment techniques will improve students' learning.
\end{abstract}

\section{Keywords}

Music, Assessment, Higher Education, Student Learning, Questionnaire, Faculty

\section{Music Assessment in Higher Education}

Assessment, as a field of study, has dramatically influenced the process of education. This field is at the center of current efforts to enhance education in the United States, and the act of assessing student learning is one of the most important responsibilities a teacher assumes [1] [2].

By definition, assessment is the systematic collection, review and use of information about educational programs undertaken for the purpose of improving student learning and development [3] [4]. Those in charge of assessment examine the practice of instructors, programs, curricula and schools, in addition to student learning. 
One of the basic tenets of current Federal education legislation is that students, schools, school districts, and state education systems report assessment practices on key educational indicators "to better empower parents, educators, administrators, and schools to effectively address the needs of their children and students" [5].

From the early part of the twentieth century, assessment has slowly worked its way into elementary and secondary schools with standardized tests such as the Scholastic Aptitude Test [6]. Several segments of educational reform occurred with tracking tests and selection in the 1950s, program accountability in the 1960s, school and district accountability in the 1980s, and standard based accountability in the 1990s [6] [7].

Assessment has gained considerable significance in higher education over the last twenty-five years. In the mid-1980s, Old Dominion University and The University of Arkansas, Little Rock, were two of the first universities to implement assessment instruments based on reading and writing skills and student development [6]. This systematic process has now become not only more prominent for college campuses as a whole, but for departments within colleges, and even the individual courses within each department. At the course level, objectives and outcomes between the teacher and the student are communicated via syllabi. The syllabus provides details of how student learning is measured and the roles of both students and instructors in the learning and assessment process [8]. Students understand their expectations at the conclusion of the course with articulated outcomes.

Music is not immune to assessment, and has been a part of the discipline for all age groups. Accountability and educational reform have made music educators mindful of the need to perform assessment that documents what a student learns in the music classroom [9]. Whether the level is elementary, secondary or post-secondary, evaluation and assessment in music education can have a significant impact on the decisions educators make to improve student learning.

Despite the increasing use of assessment throughout the United States, there are still many school systems and some universities where assessment is rarely used. Teachers today, perhaps more so than ever before, have a need to be knowledgeable of assessment instruments [10]. When it comes to the study of music at the higher education level, this author found very little information regarding assessment.

\subsection{Purpose of the Study}

The purpose of this study is to determine the type and level of assessment at selected music departments in higher education. A questionnaire was sent out to twenty-two university music departments throughout the United States. Answers to the following survey questions were sought.

1) What is your term for the "measurable" statement of what the student has learned?

2) At what level are measurable statements identified?

3) What tool(s) of the following are used to report?

4) Is this tool required?

5) To whom do you report the data and how often?

6) How is the data reviewed and used by the department?

7) Who uses the data for decisions?

8) How many units do you measure in a year?

9) At what stages are faculty involved in the process?

10) Do faculty and staff in the department provide any training/education in order to do assessment?

11) Did you provide any additional support to engage in the process such as additional staff or funding?

12) Free Response.

\subsection{Limitations of the Study}

This study only examines the assessment methodologies of music departments without an academic major in music, and NC State's sixteen peer institutions, resulting in twenty-two universities participating in this study. Second, the questionnaire focuses on general assessment questions without detail. Lastly, the final responses are only from the 2013-14 school year.

\section{Research Assessment in Higher Education}

De Grez, Roozen and Valcke [11], conducted a study that focuses on the relationship between peer, self and professional assessment of oral presentation skills and examines student awareness regarding peer assessment. Results indicate a positive relationship between self and professional assessment, but with some significant differ- 
ences. For example, oral presentation skills assessment done by students on themselves was much higher that the teachers' assessment on their students.

Falchicov and Goldfinch [12], investigated forty-eight quantitative peer assessment studies comparing peer and teacher marks which were subjected to meta-analysis. In this study, results show that peer assessments resembled more closely than teacher assessments. These results found peer assessment in the area of academics corresponded less with faculty assessments than the marking of academic products and processes. It is explained by greater student awareness with academic products and scholarly processes the students had experienced for much of their formal education, instead of academic practice which requires them to learn a new set of skills.

Topping [13] developed a systematic classification of peer assessment between students in colleges and universities, and focused on its theoretical groundwork. Results indicate a generally positive effect on peer assessment with feedback and grades on tests and in disciplines such as writing skills. These findings are typically more effective than teacher assessment. Skills such as group projects and professional presentation are much more limited. This is due to the use of computer-based peer assessment.

Hill [14] examined a new Ball State College of Business accreditation system grounded on the establishment of a unique mission and objectives statement, accompanied by an assessment program to demonstrate the achievement of the objectives. Results indicated that through the identification process of objectives and course goals, the business faculty gained genuine understanding of how significantly the accreditation process changed. The faculty also discovered how important it is that they coordinate their classroom efforts with their colleagues in order to build a better program not only for their students but ultimately for themselves. Assessment evolved from a promotion and tenure device into a tool for curriculum development and review.

\section{Research Assessment in Music}

Russell and Austin [1] composed a study surveying assessment and grading practices done by secondary music teachers. Their three research questions were: 1) What types of school district structure are used most frequently by secondary educators? 2) What types of evaluation and assessment do they use? 3) Do the results indicate any individual difference variables that influence teachers grading and assessment? Results show evaluations were a combination of criteria showing achievement (e.g., performance, skill and knowledge) and non-achievement issues (e.g., attendance, attitude and practice). Grades favored non-achievement. The process and product (i.e. concerts performed) had no influence on teachers' assessment decisions.

Leung, Wan and Lee [15] developed a study to identify the parameters for assessing musical compositions, and how assessment can aid students' learning. The study included three composer-assessors and six undergraduate music students. An assessment tool for the evaluation of the music students' compositions was established on both the macro and micro philosophies of assessing music compositions. Composers selected had experience in teaching composition at the beginning level. The composition students were in-service music teachers studying music education. None of them was a composition major, but they were expected to teach composing in schools and assess their students' composition assignments. The results indicated that both macro and micro aspects of assessing musical composition were significant but the assessors put more emphasis on the micro skills. This is because the "macro" was an interpretative aspect, requiring more "artistry" and was easier to rate high. The "micro" or "technical" aspect is fundamental to music composition, which there is clear, objective evidence of compositional techniques, making it more difficult to rate high. Constructive feedback served to help students to improve their musical works, and this tool was proven to be an effective device in assessing music composition.

Bowles [16] created a study that assessed self-expressed interests in music and identified the musical experience of attendants in adult music education. Adults who returned questionnaires identified applied study on piano, voice and guitar as their greatest interest in music participation. Most of their previous formal experiences included private lessons, participation in musical organizations, courses preferences and other experiences with similar musical activities.

Standley [17] identified the author affiliated institutions of music research by examining the number of articles published by music research scholars from research journals, and established music scholars of research eminence as determined by their citation rates. Her results showed an objective rank ordering of individuals and music institutions. These rank orderings served as a reflection where great amounts of music research have been produced and to identify individual scholars had a substantial impact on the field. A descriptive/historical analysis such as this identified the scholars, institutions, and other characteristics of those issues and topics through 
their dissemination to have been deemed important by the profession. It should be noted that rankings, and, therefore, judgments of eminence, are specific to the journals investigated and to the operational criteria for inclusion of an individual publication.

\section{Method}

A twelve item questionnaire was developed and distributed to six universities. These universities were chosen because they do not have music major but possess other strengths including several performing ensembles, many courses for students to choose from and in many cases, a minor in music. The universities include Fairfield University (Fairfield, CT), Clemson University (Clemson, SC), Purdue University (West Lafayette, IN), University of Idaho (Moscow, ID), Phoenix College (Phoenix, AZ) and Stanford University (Stanford, CA).

Cover letters and the questionnaire were emailed to the director of each music department from the first draft group on January $17^{\text {th }}, 2011$. The cover letter explained the purpose of the questionnaire and asked that the director please forward it to the faculty member in charge of assessment. Only one university returned a completed survey, so a second questionnaire was put together with an on-line program called Qualtrics, which makes the process of filling out and submitting the questionnaire much more efficient. This questionnaire, along with a new cover letter was sent again to the six campus draft group on March $11^{\text {th }}, 2011$.

In addition to putting the questionnaire onto Qualtrics, it was also updated and revised. Along with the six original universities, NC State's sixteen peer institutions were also included in this study. These universities include Cornell University (Ithaca, NY), Texas A \& M University (College Station, TX), Penn State University (State College, PA), Michigan State University (East Lansing, MI), Virginia Tech (Blacksburg, VA), Iowa State University (Ames, IA), University of Florida (Gainesville, FL), University of Georgia (Athens, GA), Georgia Tech (Atlanta, GA), University of California-Davis (Davis, CA), University of Maryland (College Park, MD), University of Wisconsin (Madison, WI), University of Minnesota (St. Paul, MN), The Ohio State University (Columbus, OH), and University of Illinois (Urbana, IL). Purdue University (West Lafayette, IN), is the only university that appears on both the piloted original six and NC State's peer institution list.

Updated cover letters and questionnaires were emailed to the Director of each Music Department on August $15^{\text {th }}, 2013$. The cover letter explained the purpose of the questionnaire and asked that the director forward it to the individual in charge of assessment. Another new cover letter and updated questionnaire were emailed to each of the six original Music Departments on August $22^{\text {nd }}, 2013$. This letter was slightly different indicating they were the "pilot" group two years before and they were a part of the current study. A reminder letter was sent out to all campuses on September $9^{\text {th }}, 2013$, asking them to respond by September $16^{\text {th }}$.

\section{Results}

This study was constructed to obtain assessment feedback from twenty-two universities nationwide. The results of this study are intended to show the amount of active assessment that is present in higher education in music at twenty-two similar universities across the country. It is intended to serve as a resource for other institutions that are looking at revising their assessment practices or looking to start assessment in their music department. Of the universities selected, nineteen $(n=19)$ are public and three $(n=3)$ are private. Of the nineteen public universities, fourteen $(n=14)$ are land grant institutions similar to NC State.

The data in this chapter are from the responses included in the questionnaires emailed to the twenty-two music department faculty members who are in charge of assessment. A copy of the Qualtrics questionnaire is given in the form of an Appendix. The Qualtrics results shown do not indicate specific university's responses. When a respondent "submits" their questionnaire, the responses go automatically into the tables shown throughout this chapter. This incorporates data from the survey which was emailed to the participants.

Eleven universities replied and sent in their feedback (50\%). This was shown on the Qualtrics tab entitled "View results." It should be noted that one university replied in the form of an email indicating that they have musical ensembles with fine instructors in charge of them, but that they do not have any faculty member in charge of assessment, and currently do not have any assessment practices. They did not reply with the questionnaire.

Most tables have less than twelve responses. This indicated that perhaps some faculty did not answer all of the questions.

Table 1 shows the responses showing the measurable term used that is related to what the student has learned. 
The responses show the majority $(n=6)$ uses outcome only. Three departments use Objective, Outcome and Goal all as the "measurable" term for student learning, and one uses objective only. No university used goal.

Table 2 results indicate the level within the campus hierarchy that measurable statements are identified.

The majority $(n=6)$ responded the department level, while three answered the majors and minors level. One indicated the college level.

Table 3 asks what kinds of tools were used to report results and data. The majority $(n=6)$ included results in their department annual report, three used a rubric explain their findings, and one school used a questionnaire. No results show if the rubric was specific to their students' needs or was more "general."

Table 4 asks if the form used in Table 3 is required. This is the one (and only) table that had all eleven responses. An overwhelming number of faculty members said yes $(n=9)$ and two said no.

Table 5 provides feedback on the question "to whom do you report the data and how often?" Five schools reported their Department Head, three reported Division Head in charge of Assessment, and two filled in "other." Neither the fill in portion for the "other" item nor the "how often" part of the question came through on the Qualtrics version of the questionnaire.

Table 6 shows result to the question "How is the data reviewed and used by the department?" Two departments said their data is collected by the assessment reviewer, processed and then passed back to the original faculty with feedback. Two departments indicated their assessment committee collects data, processed and displayed in-full for the entire faculty to observe or use. The majority $(n=6)$ responded to the "other" category. The text portion of the "other" did not come through on the Qualtrics version of the questionnaire.

Table 7 asks "Who uses the data for decisions?" Five indicated their Department Head, two said the Division Head in Charge of Assessment and one stated the faculty whose courses were used each given semester. Two schools marked "other." Again, the two "other" responses did not come through on the Qualtrics version of the questionnaire.

Table 8 shows the number of units each music department measure in one year. The majority $(n=7)$ responded with more than two. Two schools measures one unit and the other one measure two.

Table 9 indicates the stages that the faculty is involved in the process. This table only has nine responses meaning two departments did not reply. Still, it has the most spread out results. These results show that three departments answered their Department head reviews data and then passes results back to all faculty. Two marked that department head reviews data and then passes results back to faculty whose courses were used. Two states the Division Assessment Head passes results back to all faculty. Finally, two say their Division Assessment head reviews data and then passes results back to faculty whose courses were used. This shows that there is no majority among those who responded, but this does show that the entire faculty is involved in looking at assessment results.

Table 10 asks if the faculty and staff in the department are provided any training/education in order to do assessment. One indicated that all assessment training/education are available every semester. Four answered some training/education is available throughout the school year and five said little, if any training/education is available on assessment.

Table 11 looks at any additional support provided to engage in the assessment process. Additional staff or funding was mentioned as examples. Two responded that all support for assessment is available to them, nobody indicated some support with justification in writing. A large majority $(n=8)$ stated that no support is available for assessment.

Table 12 was free response, which was to be in summary style so that any institution could add any significant items. Nobody gave information on their institution's assessment process. One response stated they marked the "other" responses because a combination of the listed choices was the correct answer. This could indicate what some of the "other" responses results were in Tables 5-7).

\section{Discussion}

This study focuses on the measurable assessments, tools and procedures used in the assessment process. Measurable statements include Objective, Outcome and Goal. Possible levels identified for measurement are College, Department, Majors and Minors, and Course or GEP (General Education Program) requirements. It also lists possible tools to report assessment and asks if the tools are required.

Faculty members who assess students, are also part of the results. The faculty members in charge of assess- 
Table 1. What is your term for the "measurable" statement of what the student has learned?

\begin{tabular}{cccc}
\hline$\#$ & Answer & Response & $\%$ \\
\hline 1 & Objective & 1 & $10 \%$ \\
2 & Outcome & 6 & $60 \%$ \\
3 & Goal & 0 & $0 \%$ \\
4 & All of These & 3 & $30 \%$ \\
& Total & 10 & $100 \%$ \\
\hline
\end{tabular}

Table 2. At what level are measurable statements identified?

\begin{tabular}{cccc}
\hline$\#$ & Answer & Response & $\%$ \\
\hline 1 & College & 1 & $10 \%$ \\
2 & Department & 6 & $60 \%$ \\
3 & Majors/Minors & 3 & $30 \%$ \\
4 & Course/GEP Requirements & 0 & $0 \%$ \\
& Total & 10 & $100 \%$ \\
\hline
\end{tabular}

Table 3. What tool(s) of the following are used to report?

\begin{tabular}{cccc}
\hline$\#$ & Answer & Response & $\%$ \\
\hline 1 & Questionnaire & 1 & $10 \%$ \\
2 & Results from the Oral One-on-One Case Study & 0 & $0 \%$ \\
3 & Department Annual Planning Report & 6 & $60 \%$ \\
4 & A General Rubric That Explains “How To" with Findings & 3 & $30 \%$ \\
& Total & 10 & $100 \%$ \\
\hline
\end{tabular}

Table 4. Is this tool required?

\begin{tabular}{cccc}
\hline$\#$ & Answer & Response & $\%$ \\
1 & Yes & 9 & $82 \%$ \\
2 & No & 2 & $18 \%$ \\
& Total & 11 & $100 \%$ \\
\hline
\end{tabular}

Table 5. To whom do you report the data and how often?

\begin{tabular}{cccc}
\hline$\#$ & Answer & Response & $\%$ \\
\hline 1 & Department Head & 5 & $50 \%$ \\
2 & Division Head in Charge of Assessment & 3 & $30 \%$ \\
3 & Faculty Whose Courses Were Used Each Given Semester & 0 & $0 \%$ \\
4 & Other & 2 & $20 \%$ \\
& Total & 10 & $100 \%$ \\
\hline
\end{tabular}

Table 6. How is the data reviewed and used by the department?

\begin{tabular}{|c|c|c|c|}
\hline \# & Answer & Response & $\%$ \\
\hline 1 & $\begin{array}{l}\text { Data Is Collected by the Assessment Reviewer, } \\
\text { Processed and Then Passed Back to the Original } \\
\text { Faculty with Feedback }\end{array}$ & 2 & $20 \%$ \\
\hline 2 & $\begin{array}{l}\text { An Assessment Committee Collects Data, } \\
\text { Processed and Displayed In-Full for the Entire } \\
\text { Faculty to Observe or Use }\end{array}$ & 2 & $20 \%$ \\
\hline \multirow[t]{2}{*}{3} & Other & 6 & $60 \%$ \\
\hline & Total & 10 & $100 \%$ \\
\hline
\end{tabular}


Table 7. Who uses the data for decisions?

\begin{tabular}{cccc}
\hline$\#$ & Answer & Response & $\%$ \\
\hline 1 & Department Head & 5 & $50 \%$ \\
2 & Division Head in Charge of Assessment & 2 & $20 \%$ \\
3 & Faculty Whose Courses Were Used Each Given Semester & 1 & $10 \%$ \\
4 & Other & 2 & $20 \%$ \\
& Total & 10 & $100 \%$ \\
\hline
\end{tabular}

Table 8. How many units do you measure in a year?

\begin{tabular}{cccc}
\hline$\#$ & Answer & Response & $\%$ \\
\hline 1 & One & 2 & $20 \%$ \\
2 & Two & 1 & $10 \%$ \\
3 & More than Two (Fill in Number) & 7 & $70 \%$ \\
& Total & 10 & $100 \%$ \\
\hline
\end{tabular}

Table 9. At what stages are faculty involved in the process?

\begin{tabular}{cccc}
\hline$\#$ & Answer & Response & $\%$ \\
\hline 1 & $\begin{array}{r}\text { Department Head Reviews Data and Then Passes } \\
\text { Results Back to All Faculty }\end{array}$ & 3 & $33 \%$ \\
2 & $\begin{array}{r}\text { Department Head Reviews Data and Then Passes } \\
\text { Results Back to Faculty Whose Courses Were Used } \\
\text { Division Assessment Head Reviews Date and Then } \\
\text { Passes Results Back to All Faculty }\end{array}$ & 2 & $22 \%$ \\
4 & $\begin{array}{r}\text { Division Assessment Head Reviews Data and Then Passes } \\
\text { Results Back to Faculty Whose Courses Were Used }\end{array}$ & 2 & $22 \%$ \\
& Total & 9 & $100 \%$ \\
\hline
\end{tabular}

Table 10. Are faculty and staff in the department provided any training/education in order to do assessment?

\begin{tabular}{cccc}
\hline$\#$ & Answer & Response & $\%$ \\
\hline 1 & All Assessment Training and Education Are Available & Every Semester & $10 \%$ \\
2 & Some Training and Education Is Available throughout \\
the School Year & 4 & $40 \%$ \\
& Little, If Any Training and Education Is Available & 5 & $50 \%$ \\
\hline
\end{tabular}

Table 11. Are you provided any additional support to engage in the process such as additional staff or funding?

\begin{tabular}{cccc}
\hline$\#$ & Answer & Response & $\%$ \\
\hline 1 & All Support for Assessment Is Available & 2 & $20 \%$ \\
2 & Some Support with Justification in Writing & 0 & $0 \%$ \\
3 & No Support Is Available & 8 & $80 \%$ \\
& Total & 10 & $100 \%$ \\
\hline
\end{tabular}

Table 12. Free response-This last item is voluntary and is in summary style so that you may add any significantitems to your university’s assessment process. Thank you for your time?

\section{Text Response}

FYI: I Answered Some of the Questions above as “Other” Because a Combination of the Items Was the Correct Answer. 
ment include the department or division head and the individual in charge of assessment. Music faculty involvement in the assessment process includes those who apply assessment to their teaching of students with various kinds of measurement tools. Other music faculty members can benefit from decisions made by comparing their own students learning to the students whose learning was measured during the assessment process.

Table 1 asks for the "measurable" statement of what the student has learned. Six assessment faculty say "outcome" while three say "all of these." Outcomes are very specific tasks measured to see if a student has learned with success. A typical university syllabus lists outcomes in order with a heading like "By the end of the term the student will be able to...” and then lists each outcome with numbers or bullet points. Therefore it is understandable why the majority list outcome as their measurable statement.

Results in number Table 2 show the level that measurable statements are identified. Six say "department” while three say "major/minor." Here again, these responses are similar to outcomes; departments are usually more specific in their expectations with their degree programs. Academic majors and minors within a department are even more specific. This facilitates the outcome creation and makes the assessment process more measurable.

Reporting the process with the tools used was also straightforward. Six used a department annual planning report and three used a general rubric that explains "how to" with findings. In Table 4, nine faculty stated that the tool was required. A correlation between both questions is not known. However, this demonstrates the importance of assessment routines by documenting the process from year to year. This gives assessment faculty the ability to compare results and to see if recommendations were fulfilled from previous years.

When it comes to reporting data to an administrator from the faculty member in the process of assessment in Table 5, ten faculty members responded. Five reports to the Department Head and three stated the results were given to the individual in charge of assessment. These two were the most common, but two checked "other." Results indicate that upper level administrators are aware of assessment processes and review the methodology that faculty are using and study their results.

Results in Table 6 which asks how is the data reviewed and used by the department also had ten responses. Two departments said their data is collected by the assessment reviewer, while two stated an assessment committee collects the data, processes and displays the data to the entire faculty. Six campuses selected "other." It is not known how they review the data. However, this shows that groups, or in some cases their entire faculty were involved in assessment.

Concerning decisions made with the assessment data, the Department Head option had five responses, the Division Head in charge of Assessment had two responses and the faculty whose courses were used each semester had one response. "Other" was selected by two. This suggests that the upper level administrators are aware of the decisions made based on assessment results, with some faculty input.

Seven faculty indicated that the number of units measured was more than two. One marked two and two said one. The "units" are usually outcomes, but could be objectives or goals. Results show the majority have a commitment to evaluating three or more department areas (e.g., majors, minors, specific course, etc.) which are satisfactory and identifies areas that need improvement with recommendations.

Faculty involvement differed. Answers indicating the Department Head reviews data and then passes results back to all faculty had three responses. The remaining other responses had two. Only nine faculty responded with no majority. However, Table 9 demonstrates that the entire faculty is involved in analyzing assessment results and considers making changes to the target improvement areas.

Training and support given to the music department relating to assessment was not as positive. One university reports that all training is available, four state availability of some assessment training, and five indicate little, if any training and education availability. Feedback indicating support was less positive. Two remarked that all support for assessment was available, yet eight said no support was available.

The results of this study indicate that assessment is going on in higher education in music. Although there were only eleven institutions involved in the study, every university indicated that they were doing some kind of assessment in music. The degree of assessment varies from campus to campus. Assessment training and support was limited. But, according to the Qualtrics survey, eleven music departments nationwide feel the need (and responsibility) to examine what and how they are teaching and then to come up with decisions on how to improve their teaching. Further, they feel that implementation of reviewed assessment techniques will improve students' learning. 


\section{Topics for Further Study}

1) Survey more music departments on assessment, and how they utilize assessment results.

2) Replicate this study with the universities surveyed in five years to compare updates and changes made in assessment.

3) Compare the Music Department's assessment with other departments within each university (arts or nonarts) to see:

a) How much the Music Department is doing when looking at other departments.

b) How each university as a whole is doing with assessment practices.

\section{Acknowledgements}

The author would like to thank the following for their assistance in this study's preparation: Jason De Rousie for the initial review and his expertise in assessment, J. Mark Scearce and Marcia Toms for following reviews, questions and comments. Special thanks go to Gary Beckman, for his critical reviews and comments on presentation and manuscript.

\section{References}

[1] Russell, J.A. and Austin, J.R. (2010) Assessment Practices of Secondary Music Teachers. Journal of Research in Music Education, 58, 37. http://dx.doi.org/10.1177/0022429409360062

[2] Miller, L. and Gronlund (2009) Measurement and Assessing in Teaching. 10th Edition, Pearson Education, Upper Saddle River.

[3] Palomba, C.A. and Banta, T.W. (1999) Assessment Essentials: Planning, Implementing, and Improving Assessment in Higher Education. Jossey-Bass Publishers, San Francisco.

[4] Marchese, T.J. (1987) Third Down, Ten Years to Go. AAHE Bulletin, 40, 3-8.

[5] US Department of Education (2011) No Child Left Behind.

[6] Cobb, S. (2004) History of Assessment Practices in the United States.

[7] Linn, R.L. (2000) Assessment and Accountability. Online, 29, 2.

[8] Habanek, D.V. (2005) An Examination of the Integrity of the Syllabus. College Teaching, 53, 2. http://dx.doi.org/10.3200/CTCH.53.2.62-64

[9] Asmus, E.P. (1999) Music Assessment Concepts. Music Educator's Journal, 86, 2. http://dx.doi.org/10.2307/3399585

[10] Rudner, L.M. and Schafer, W.D. (2002) What Teachers Need to Know about Assessment. National Education Association, Washington DC.

[11] De Grez, L., Roozen, I. and Valcke, M. (2012) How Effective Are Self- and Peer Assessment of Oral Presentation Skills Compared with Teachers’ Assessments? Active Learning in Higher Education, 13, 129-142. http://dx.doi.org/10.1177/1469787412441284

[12] Falchicov, N. and Goldfinch, J. (2000) Student Peer Assessment in Higher Education: A Meta-Analysis Comparing Peer and Teacher Marks. Review of Educational Research, 70, 287. http://dx.doi.org/10.3102/00346543070003287

[13] Topping, K. (1998) Peer Assessment between Students in Colleges and Universities. Review of Educational Research, 68, 249-276. http://dx.doi.org/10.3102/00346543068003249

[14] Hill, I.B. (1996) Setting the Context for Assessment. Assessment in Practice: Putting Principles to Work on College Campuses. Jossey-Bass Publishers, San Francisco.

[15] Leung, C., Wan, Y. and Lee, A. (2009) Assessment of Undergraduate Students' Music Compositions. International Journal of Music Education, 27, 250-268. http://dx.doi.org/10.1177/0255761409337275

[16] Bowles, C.L. (1991) Self-Expressed Adult Music Education Interests and Music Experiences. Journal of Research in Music Education, 39, 3. http://dx.doi.org/10.2307/3344719

[17] Standley, J.M. (1984) Productivity and Eminence in Music Research. Journal of Research in Music Education, 32, 149. http://dx.doi.org/10.2307/3344834 